\title{
WEIGHT MANAGEMENT WITH DAILY CONSUMPTION OF RECOMMENDED VEGETABLE INTAKE AMONG OVERWEIGHT WOMEN IN JAKARTA
}

\author{
Indri Kartiko Sari'), Diah Mulyawati Utari²), Shigeru Yamamoto') \\ 1)International Nutrition, Graduate School of Human Life Science, Jumonji University \\ 2)Public Health Nutrition Department, Faculty of Public Health, Universitas Indonesia
}

\begin{abstract}
Background: Strengthening health promotion and disease prevention will provide extraordinary benefits. Promoting health and preventing diseases are major investments in reducing the burden of public health services. As part of Gerakan Masyarakat Hidup Sehat (GERMAS), the intake of vegetables and fruits of $250 \mathrm{~g}$ and $150 \mathrm{~g}$ is recommended to maintain health through lifestyle improvements from daily eating habits. This study aimed to observe the effect of daily consumption of recommended vegetables intake among overweight women in Jakarta.
\end{abstract}

Subjects and Method: This was an experiment study. Twenty overweight women aged 55year-old was selected for this study. The dependent variables were body weight, body mass index (BMI), and energy intake. The independent variable was vegetables consumption. 400 $\mathrm{g}$ vegetables were added into their daily meals for three weeks. Body weight and BMI were measured using weight scale. Energy intake were measured by the 3-day food records over 24hour recall. Mean difference of body weight, body mass index, and energy intake before and after treatment were analyzed by t-test.

Results: Women body weight $(\mathrm{kg})$ after treatment (Mean=62; $\mathrm{SD}=6)$ was lower than before (Mean $=64 ; \mathrm{SD}=6.4)$ and it was statistically significant $(\mathrm{p}=0.001) . \mathrm{BMI}\left(\mathrm{kg} / \mathrm{m}^{2}\right)$ after treatment (Mean=28.4; $\mathrm{SD}=2.4$ ) was lower than before (Mean=29.3; $\mathrm{SD}=2.5$ ) and it was statistically significant $(\mathrm{p}=0.001)$. Energy intake (kcal) after treatment $(\mathrm{Mean}=1,608 ; \mathrm{SD}=130)$ was lower than before (Mean=2,080; $\mathrm{SD}=302)$ and it was statistically significant $(\mathrm{p}=0.001)$.

Conclusion: Vegetables intake is commended intake of vegetables and fruits can help weight management in overweight women by reducing energy intake and increasing fiber intake.

Keywords: weight management, vegetable intake, overweight, BMI, overweight

\section{Correspondence:}

Indri Kartiko Sari. Graduate School of Human Life Science, Jumonji University. Saitama, Japan. Email: indri.kartiko@yahoo.com. Phone: +6285691068652

The $7^{\text {th }}$ International Conference on Public Health

Solo, Indonesia, November 18-19, 2020|330 https://doi.org/10.26911/the7thicph.04.15 